\title{
Thinspiration vs. thicksperation: Comparing pro-anorexic and fat acceptance image posts on a photo-sharing site
}

\author{
Sarah-Rose Marcus \\ Department of Communication and Information, Rutgers University, New Brunswick, NJ, United States
}

\begin{abstract}
This study is among the first to compare the social media content of these two online communities related to body image: The pro-anorexic community and the fat acceptance community. I used a content analysis of 800 Instagram posts and compared how both communities conveyed their social identities and provided social support. I found that fat acceptance members identified with their community through hashtags related to positivity and self-love, while pro-anorexics identified with their community through posts related to "thinspiration" and negativity. Members of the fat acceptance community distinguished against outsiders by attempting to reframe beauty, while members of the pro-anorexic community distinguished against outsiders by arguing with recovered anorexics. Lastly, both communities provided support by complimenting users' appearances and providing informational resources on how to maintain one's body image. Members of the proanorexic community also circulated network support by promoting the weight-loss buddy system of "ana buddies." I propose for future researchers to triangulate these findings with interviews and ethnographic studies to further understand community values. This knowledge provides useful insight into the way in which stigmatized communities use technology to maintain their social identities and enhance their support.
\end{abstract}

Keywords: Social identity; body image; photo sharing platforms; online communities; social support

\section{Introduction}

As social network sites continue to grow as a prominent space for interaction, individuals can connect with other people who share similar goals, interests, values and worldviews. Numerous communities have also emerged online in order to provide support for those who are struggling with particular issues. One such community is the pro-anorexic community, which refers to a group of anorexics who share the perspective that having an eating disorder is a lifestyle choice, as opposed to a mental illness (Lipczynka 2007; Lyons, Mehl, \& Pennebaker, 2006). This group typically connects online through various pro-anorexic websites (Gavin, Rodham, \& Poyer, 2008) and has more recently begun communicating in various ways through social media (Juarascio, Shoaib, \& Timko, 2010). There is no equivalent type of group offline, as the Internet enables anorexics from all over the world to discuss these issues (Warin, 2009). The purpose of these online discussions is to promote the maintenance of the group's eating disorders and to encourage members to continue in their quest for weight loss. This community has received widespread attention from media outlets and scholars who convey concern about the dangerous and unhealthy content that they share on the Internet (Boero \& Pascoe, 2012; Peng, 2008). 
Another online community has recently begun to receive public notice due to its shared perspective against the ideals of thinness. This community has been named the fatosphere and is composed of bloggers and Internet users who are overweight and promote the ethic of fat acceptance. The fatosphere aims for acceptance of one's body and rejects the notion that one's body is unacceptable if it does not conform to societal norms of being thin (Dickins, Thomas, King, Lewis, \& Holland, 2011). Although this movement is less widely known than the proanorexic movement, it is slowly beginning to receive attention. Public advocates have received recognition from the New York Times and numerous other media outlets over the past several years (Katz, 2009; Rabin, 2008). Similar to the pro-anorexic movement, the fatosphere has also been publicly critiqued for its values and ideologies (Bowers, 2010; McDonell-Parry, 2009). For example, the premise of the movement has been labeled unhealthy by multiple bloggers and health magazines.

Most studies on both pro-anorexic and fat acceptance communities have focused on the way in which messages are conveyed through language on websites, blogs and social network sites (Giles, 2006; Gavin et al., 2008; Lyons et al., 2006; Tuefel et al., 2013). This research overlooks how these groups use visual communication for the purpose of spreading body image ideals. Individuals develop a particular body image based on how they view themselves in the mirror and make evaluations about their physical shape. Therefore, it is surprising that the current literature on these two communities has not centered on the images displayed on social network sites.

An important way in which members of the pro-anorexic community seek to motivate each other is by sharing thinspiration, or images of very thin women (Chesley, Alberts, Klein, \& Kreipe, 2003; Harshbarger, AhlersSchmidt, Mayans, Mayans, \& Hawkins, 2009; Norris, Boydell, Pinhas, \& Katzman, 2006). Pro-anorexic members of social network sites such as Instagram tend to circulate this content using hashtags such as \#proanaa, \#thinspoooo and \#anatips. Similarly, members of the fatosphere share images designed to promote body acceptance through hashtags such as \#bodypositive, \#bbw (big, beautiful women) and \#effyourbodystandards. Individuals in each community also bring attention to their own standard of beauty through the captions in their pictures.

Lastly, to my knowledge, research has yet to compare the way in which both of these movements convey contrasting ideals of body image. This gap is interesting given the increasing public curiosity about each of these communities. Assessing self-presentation practices of both pro-anorexic and fat acceptance movements can help shed light on how communities identify on the basis of body image. In this paper I uncover the behaviors of both communities on the photo-sharing platform of Instagram. I reveal the way in which stigmatized individuals use strategies to connect with their in-groups, distinguish against outsiders and provide social support.

\section{Social Identity and Body Image}

This paper views the mediated communication of body image movements through the perspective of social identity theory (Tajfel, 1978; Tajfel \& Turner, 1979). One's social identity refers to a person's knowledge that he or she belongs to a social category or group that possesses similar qualities, values and worldviews (Hogg \& Abrams, 1988). Individuals' attitudes and beliefs tend to align in the direction of the social groups to which they belong. The context of social media provides an important space for individuals to publicly depict affiliation to particular social categories. These types of forums provide a sense of communicative interactivity, which allows members to engage in community building (Sundar, Edwards, Hu, \& Stavrositu, 2007). Research on online communities has found that users collaboratively construct their identities in a performed manner. For example, Stommel and Koole's (2010) conversation analysis of newcomer interactions on pro-ana websites found that they addressed other members solely as a group, while Haas, Irr, Jennings, and Wagner (2011) found that proanas co-constructed their personal identities.

Social identity formation begins with the process of self-categorization (Hogg \& Abrams, 1988; Stets \& Burke, 2000). Similar to the way in which we categorize objects, we categorize people into groups in order to provide a simplified understanding of our environment (Tajfel \& Turner, 1979). We then expect those groups to have similar habits of communication and accentuate their similarities. For example, research on pro-ana websites has found that individuals categorize themselves based on their weight, space, social interactions and dedication to perfection (Figueras Bates, 2015; Knapton, 2013). Additionally, studies on the fat acceptance movement indicate that members tend to categorize themselves as an "autonomous, self-transparent and self-authoring 
community" (Murray, 2005, p. 275). This type of accentuation is more prominent when the categorization is salient to the individual's identity (Tajfel, 1969). For example, a woman who is less defined by her body weight might be less inclined to identify with members of the fat acceptance movement. Similarly, a woman who does not advocate for the anorexic lifestyle will be less inclined to call herself pro-anorexic.

Members of each of the movements in this study are likely to share similar communication practices with their communities on social network sites in order to accentuate those similarities. One way in that this occurs is by identifying shared behaviors. Members of pro-anorexic communities will often disclose anorexic behaviors of low calorie intake by revealing their food diaries and discussing plans for achieving an extremely low "goal weight" (Borzekowski, Schenk, Wilson, \& Peebles, 2010; Juarascio et al., 2010). These users will provide proof of their membership by discussing physical symptoms of anorexia, such as the loss of hair, weight and feelings of fatigue (Gavin et al., 2008; Riley, Rodham, \& Gavin, 2009). Newcomers in these online communities must also legitimize their position by performing in ways that would allow them to be accepted (Boostrom, 2008; Giles, 2006; Stommel \& Koole, 2010; Stommel \& Meijman, 2011; Williams \& Riley, 2013). For example, Williams and Riley (2013) found that new members of pro-ana websites legitimized their position by discussing psychological characteristics of eating disorders (such as issues of control, obsession and feelings of difference).

Research on fatosphere blogs has found that users connect over the common experience of feeling uncomfortable about one's body at an early age (Dickins et al., 2011). Members of the fat acceptance community may also characterize themselves as having similar beliefs regarding social norms and stigmatization. For example, members of this community tend to align with one another based on their views of feminism, patriarchy and beauty ideals (Bartky, 1990; Brown, 1989; LeBesco \& Braziel, 2001; Orbach, 1978). For example, Gurrieri and Cherrier (2013) found that fat acceptance bloggers used similar strategies to challenge the cultural ideologies of what it means to be feminine and beautiful (such as posing in bikinis). Fat acceptance members also share the behavior of "coming out as fat" as a way of telling their audience that they do not intend to change their physical shape (Saguay \& Ward, 2011).

Although each individual's personal experience varies, both communities stress common themes in order to form a sense of solidarity. In light of these behaviors, I ask:

RQ1: How do pro-anorexic and fat acceptance image posts accentuate similarities to their ingroups?

In order to define who belongs inside a group, the group distinguishes which members are authentic. Members of an online platform will police individuals who do not conform to these rules by responding that certain comments are out of line with that particular community (Williams \& Riley, 2013). For instance, members of online pro-anorexic communities tend to call others "wannarexics" or "fakers" when they do not seem knowledgeable about having an eating disorder and seem noncommittal to the anorexic lifestyle (Borzekowski et al., 2010; Giles, 2006). Research has found that members of online mental health communities will take the position of diagnosing other members to demonstrate their legitimacy (Giles \& Newbold, 2010).

Similarly, members of the fatosphere make a distinction between the characteristics of their in-group and the characteristics of outsiders. An outsider would be someone who has internalized the stigma that being fat is unhealthy and socially undesirable. For example, fatosphere blog communities will automatically remove any content that indicates self-loathing messages (Dickins et al., 2011). An outsider of this community would be someone who succumbs to ideologies surrounding being overweight and being unhealthy (Anderson, 2012; Campos, 2005; Ernsberger \& Haskew, 1997; Harding, 2007; Satinsky \& Ingraham, 2014). Furthermore, outsiders are also measured based on their willingness to publicly campaign for a political agenda to change social norms (Kirkland, 2008; LeBesco, 2004; Sobal \& Maurer, 1999). In relation to these distinctions, I ask next:

RQ2: How do pro-anorexic and fat acceptance image posts accentuate the differences between their in-group and their out-groups?

A final presupposition of social identity theory is that social groups are motivated to raise their self-esteem and reach self-enhancement (Tajfel, 1979). This motive becomes important for both groups in this study because 
they have been stigmatized in regards to their health, lifestyle and physical appearance. Both overweight and anorexic individuals have been reported to suffer from low self-esteem, higher levels of strain and lower levels of social support (Carr \& Freidman, 2005; Harper, Sperry, \& Thompson, 2008; Tiller, Schmidt, Ali, \& Treasure, 1995; Tiller, Sloane, Schmidt, \& Troop, 1997; Wardle, Waller, \& Fox, 2002). Thus, these stigmatized communities can help raise their self-esteem by finding others who share a similar worldview (Goffman, 1963).

Members of both pro-ana and fat acceptance communities tend to seek support from one another (Tierney, 2008). Studies have shown that digital media has been a helpful resource for stigmatized individuals to find this support (Bane, Haymaker, \& Zinchuk, 2005; LaCoursiere, 2001; Thurlow \& Bell, 2009; Yeshua-Katz \& Martins, 2013). For example, Mantella (2007) found that over half of pro-ana bloggers reported that they were motivated to blog in order to receive social and emotional support. Members of online pro-anorexic communities often feel a sense of camaraderie with others who suffer from similar issues (Csipke \& Horne, 2007; Dias, 2013; Falk, 2001). These types of communities provide anorexics with a sense of temporary relief from the hostility they experience in their day-to-day lives (Brotsky \& Giles, 2007). That said, these forms of support may not necessarily provide helpful outcomes for one's physical and psychological well-being. For example, Tong, HeinemannLafave, Jeon, Kolodziej-Smith and Warshay (2013) found that pro-anorexic bloggers supported each others' illness by discouraging users to interact with any outside family members or physicians who might disagree with their values.

Overweight individuals who participate in the fatosphere have also articulated the importance of belonging to a network that provides support (Dickins et al., 2011; Harding \& Kirby, 2009; Myers \& Rothblum, 2010). Studies have shown that overweight individuals are less likely to have depressive symptoms if they belong to a supportive network (Zeller \& Modi, 2006). Overweight individuals can receive support by circulating comments that accept each others' bodies and encourage each other to reject their offline marginalized identities (Smith, Wickes, \& Underwood, 2015). For instance, Chou, Prestin and Kunath (2014) found that fat acceptance messages on Twitter were often re-tweeted to enhance positive sentiment.

One way in which support has been measured on social network sites is through the quality of verbal messages (Juarascio et al., 2010). Although photo-sharing sites such as Instagram are image based, individuals can lend support through the comment feature. Additionally, the "like" button is one of the most common forms of feedback on Instagram, which sees approximately 3.5 billion "likes" generated per day (Instagram, 2016). Therefore, this study is interested in how the images posted by both communities might generate support from their in-groups. This leads to my final question:

RQ3: In what ways do pro-anorexic and fat acceptance image posts receive support from their networks?

\section{Method}

\section{Sample}

In order to obtain a generalizable sample of both communities, I first sought out the most popular hashtags for each group. This process began by searching the most prevalent hashtags on the website of tophashtags.com/instagram. This search engine was the most appropriate because it continuously updates the number of images that contain each hashtag and ranks the hashtags by their popularity. I started the search with the hashtags of \#bodypositive for the fat acceptance community and \#proanaa ${ }^{1}$ for the pro-anorexic community. The site revealed 202 of the most popular hashtags for the bodypositive community and 94 of the most popular hashtags for the proanorexic community.

The hashtags were narrowed down based on the appropriateness of posts for each community and the quantity of images. A primary criterion of exclusion emerged in relation to the relevance of topics surrounding either body positive messages or pro-anorexic messages. For example, the hashtag of \#thickspo was excluded from the fat acceptance criterion because its images tended to depict weight loss and workout content, rather than 
body acceptance content. Similarly, hashtags such as \#anorexic or \#bulimic were excluded from the proanorexic community because they displayed posts from users who had recovered from their eating disorders and did not advocate for the anorexic lifestyle.

For the fat acceptance community, the final hashtags resulted in the following: \#Bodypositive, \#effyourbeautystandards, \#celebratemysize, \#honormycurves and \#bbw. For the pro-anorexic community, the final hashtags resulted in the following: \#Proanaa, \#thinspooo, \#thighgap, \#anatips, and \#anabuddy. Eighty of the most recent posts were sampled from each hashtag, which resulted in 800 total posts (400 from the fat acceptance community; 400 from the pro-anorexic community). Posts were excluded from the selection of body positive images if they featured pornographic content or consumer content from plus size stores. Similarly, posts were excluded from the selection of pro-anorexic images if they used anorexia as a subtopic for posts that centered on depression, anxiety and suicide. The data collection occurred on 5 randomly selected dates between April and May of 2015: April 7 ${ }^{\text {th }}, 2015$; April 16 ${ }^{\text {th }}, 2015$, April 27 ${ }^{\text {th }}, 2015$ and May $2^{\text {th }}, 2015$.

All posts analyzed were from public user accounts. No deception was involved in entering the communities due to the public availability of their hashtags. A choice was made to rename all user names with pseudonyms and to reword all quotes so that users would be unsearchable. All user names were saved on a separate, secure computer and then discarded after the data collection period. I opted not to take screenshots to protect the privacy of the content for users in both communities.

\section{Codes}

Due to the lack of studies on both of these communities together, I chose to analyze the data using the constant comparative method (Glaser \& Strauss, 1967). The coding occurred through an iterative process that compared (a) image types/aesthetics, (b) captions, (c) hashtags and (d) comments. For both RQ1 and RQ2, I began with open coding in order to build, name and ascribe attributes to categories. I began with 40 posts from each community to develop a codebook in relation to each of their tactics of social identity.

Initial codes were developed based on each group's shared use of aesthetic choices (such as bright colors, black and white, mirror shots), types of body displays (such as full body, stomach, body and face, bones), group norms and affiliation (such as re-occuring hashtags and message types) and forms of inter-group conflict (such as insults, objections and defense). This codebook began with a list of 38 codes for both of these communities. I then used far-out comparisons (Corbin \& Strauss, 2014) by comparing the two contrasting communities for their similarities on a conceptual level. I assessed whether the codes appeared in one, both or neither of the communities. During the axial coding stage, I coded the remaining 360 posts for each community and refined the initial codebook. I narrowed down and collapsed codes if they were found to represent the same strategy to convey social identity. For example, I collapsed the code of "darkness filter" with the code of "negativity" because I found it to be used as a way for pro-ana's to convey their negativity. Similarly, I collapsed the codes of "bones," "full body" and "beauty and bones" after interpreting that pro-ana's were using these body displays to illustrate their standards of beauty.

The selective coding stage refined the subcategories at a conceptual level based on the categories for the first two research questions (including identification and distancing). Thus, I rearranged the codebook of subcategories in relation to their salience for each particular research question. As such, codes such as "positivity and self-love" were placed as a subcategory of identification, while codes such as "reframing beauty" were placed as a subcategory of distancing (for fat acceptance). This process ended with 13 codes in total for both RQ1 and RQ2.

Lastly, RQ3 asked how members of each community provided social support. I coded this research question using Cutrona and Suhr's (1994) 5 categories of support: (a) informational support (with subcategories of suggestions/advice, situation appraisals, teaching and references), (b) emotional support (with subcategories of relationships, sympathy, empathy and encouragement), (c) esteem support (with subcategories of compliments and validation), (d) network support (with the subcategory of companionship), and (e) tangible assistance. This framework was selected due to findings that pro-anorexic bloggers have provided one another with these types of support in previous research; for example, they have circulated informational support through diet tips and 
emotional support through expressions of sympathy (Tong et al., 2013). Extending this notion to the fat acceptance posts provided a fruitful way to compare and contrast whether these categories of support were salient for both communities.

A pilot test using $10 \%$ of posts from each community (40 posts from the pro-ana community; 40 posts from the fat acceptance community) found that this framework was sufficient for both communities. However, each subcategory of support was elaborated based on unique patterns within each community. For example, the subcategory of validation took the form of encouraging comments for the fat acceptance community and took the form of discussions of "likes" for the pro-ana community. I coded support in the linguistic content of user comments and analyzed each comment by the unit of one sentence. The image posts and captions were considered during this process to provide a larger context of the social support provided. For example, a fat acceptance post of a user wearing a bikini provided context for comments that included informational support regarding where to buy plus-size clothing.

\section{Results}

\section{In-Group Association: Fat Acceptance}

Identification. One way in which the fat acceptance community accentuated similarities (RQ1) was through identifying hashtags. As seen in table 1, identification posts consisted of $65 \%$ the fat acceptance posts. The hashtags used reflected different nicknames for the community, which derived from the group's characteristics, traits and values. The most general community identifiers were hashtags such as \#fatacceptance, \#bodypositive and \#bodypositivity. Other identifiers referred to the close bond of the community by using symbolic references to family. For example, a prevalent hashtag was \#pizzasisters4life, which indicated the fat acceptance community's life-long bond. The identifiers also referred to the group's physical attributes by using hashtags such as \#curvygirls, \#thickgirls and \#curvydolls. Lastly, these identifiers reflected a positive framing of the community with hashtags related to the term, "bbw," which stands for big beautiful women (such as \#teambbw).

Positivity and self-love. Members of the fat acceptance movement used images to show how they had internalized the fat acceptance mantra of positivity. As seen in table 1, this was the second highest percentage of posts for this community (57\% of posts). These posts typically used upbeat captions and hashtags that pointed to a shared sense of happiness and positive energy. For example, one user shared a screenshot of a recent post (on another social media platform) that showed her posing in front of the mirror with her midriff exposed. She captions the image: "Guys, I took a selfie with my tummy and feel good about it!" This post included several uplifting emojis to reiterate the message, such as the sunshine emoji and the heart emoji. Other users tended to supplement their posts with hashtags such as \#happiness, \#happy \#goodvibes and \#positivity. These hashtags indicated the importance of spreading optimistic messages for this particular community.

Similarly, this sample tended to emphasize self-love within their images. A recurring motif was based on loving oneself and accepting one's flaws. For instance, one user shared a photo-collage that showed various close-up selfie's of her face. She captioned the picture: "This is just plain me, nothing glamorous, no makeup. I am still beautiful, confident and fabulous!" This user's emphasis on wearing no makeup suggests the value of natural beauty and of not trying to alter or enhance her looks. This points to a potential belief within the fat acceptance movement that individuals should not try to change themselves in order to fit in with society's beauty standards. The hashtags that typically coincided with these types of posts conveyed the ethic of self-acceptance (such as \#acceptyourself, \#respectyourself, and \#lovetheskinyourein). Other hashtags, such as \#confidence, \#selfesteem and \#bodyesteem also expressed the importance of having an inner sense of self-esteem.

\section{In-Group Association: Pro-Ana}

Identification. Similar to the fat acceptance posts, the pro-anorexic posts used certain labels to convey their role in the community (54\% of posts; as seen in table 2). These hashtags were often simple labels such as \#proanaa and \#promia. Other labels were developed to convey the secrecy and exclusivity of the community 
(such as the hashtag of \#secretsociety123). The secret aspect of these labels is probably due in part to outside users reporting this community for circulating unhealthy content. Other users illustrated their engagement in the community's practices with hashtags that showed their diet restrictions. For example, users labeled their pictures with hashtags such as \#starving, \#hungry, \#anadiary and \#abcdiet.

Weight loss ethic and thinspiration. Members showed their community affiliation by posting images related to the importance of dramatic weight loss and the motivation to restrict one's food (61\% of posts). This discussion was reflected in images that described users' weight loss diaries. For example, some users created memes that showed the days of the week and the number of calories that were consumed each day (i.e. Monday: 300 calories). Other users shared screenshots of their restricted food (such as a bowl of apples) and labeled them with the number of calories they had consumed that day (i.e. 80 calories). The pro-anorexic image posts also displayed authenticity by revealing proof of users' dramatic weight loss and emaciated status. These pictures were typically close-up shots of particular body parts, such as users' collarbones, hipbones and rib cages.

Lastly, users tended to promote the ethic of thinspiration by sharing images of emaciated figures. Thinspiration images served to both motivate users to maintain their diets as well as to outline the standards of beauty in the group. These pictures were either of famous models or unknown thin individuals. Most of the bodies displayed were extremely underweight and had a very low body mass. These pictures may appear unattractive, unhealthy and grotesque to members of the outside world but seem to appear attractive and desirable for pro-anorexic individuals.

Negativity. In contrast to the fat acceptance ethic of positivity and acceptance, the pro-anorexic images tended to convey an ethic of negativity and discontent (37\% of posts). One way that this was depicted was through the coloring of the images, which often used the "black and white" filter. These pictures also tended to use dark shading, which may have been intentionally manipulated through the application's "brightness" feature. These images often utilized negative hashtags such as \#depression, \#depressed and \#sad and featured negative emojis such as the skeleton emoji and the sad face emoji.

Members of the pro-anorexic community also stressed the importance of self-harm. A number of the images depicted self-inflicted cuts on users' thighs and stomachs. Users also included hashtags such as \#killme, \#selfharmmm, \#selfhate, \#bleeding and \#cuts and often used the gun or bomb emoji. These images also included captions related to self-disdain. For instance, one user wrote: "I can't believe I'm 121 pounds...I hate myself for being so gross." These posts provide an opportunity for users to share the pro-anorexic standard of not accepting one's current weight.

\section{Out-Group Rejection: Fat Acceptance}

Rejecting the status quo. Findings on RQ2 showed that the fat acceptance community distinguished against outsiders by discussing the community's rejection of stigma (37\% of posts). These posts typically used hashtags such as \#effyourstandards, \#effyourbeautystandards and \#effyourbodystandards. This suggests a direct response to society's pressure to have a thin body type. For instance, one user captioned her image with the following:

We need to stop taking on society's shaming of the female form and making us believe that we're not skinny enough, tall enough or beautiful enough... I don't hate on other peoples' bodies so why does mine make an exception?

The quote above suggests the emphasis to directly reject the shame that is often imposed onto members of the fat acceptance community. One common method was to engage in social competition, which occurs when group members actively work to change the status quo (Ellemers \& Haslam, 2011). User posts shared hashtags related to social change, such as \#breakbarriers, \#legalizethunderthighs and \#breaksocietiesmold. A common meme that was circulated contained the following quote: "Lets overthrow social norms together." A number of memes were remixed and recreated to display an unintended message. One meme repurposed a message related to achieving a summer body with the quote: "Need to be skinny for summer." The word "skinny" is crossed out and 
replaced with the word, "bodypositive," while the word "summer" is replaced with "always." This suggests the direct intention to shift society's motivations and mindsets towards body positivity.

Another tactic used by members of the fat acceptance community was the attempt to change the social norms regarding self-exposure and shame. One way that this occurred was through the trend of the "fatkini." Overweight users would display their bodies wearing a bikini in order to make a statement of self-acceptance. One user captioned her "fatkini" picture with the following statement:

Why should I wear a 1 piece just because I'm not the 'ideal' body? I normally wear a one piece when I go to the beach. But this summer I'm going to try to wear my \#fatkini and enjoy myself...\#effyourbeautystandards!

Reframing beauty. Fat acceptance posts attempted to distance themselves from other groups by engaging in the tactic of social creativity. This occurs when members of social groups attempt to redefine the group comparison by representing the in-group with positive characteristics (Ellemers \& Haslam, 2011). These types of posts made comparisons between the in-group and outside groups by reframing the fat acceptance group as the more desirable group ( $45 \%$ of posts). One tactic involved changing the meaning of beauty by advocating for a larger body type. Users often posted hashtags that associated being big with being beautiful, including \#bbw, \#bigisbeautiful, \#bigbeautifulwoman and \#plussizedbeauty. These images aimed to celebrate fatness and convey its superiority. For instance, one user posted a bikini image with the caption: "Lets celebrate our curves guys! \#honormycurves."

Comparisons with other women. Members of the fat acceptance community tended to make positive comparisons against other women in order to accentuate the differences among groups (35\% of posts). One way in which this occurred was by arguing that other women did not love themselves. One user wrote: "Sorry if my self love gets in the way of all of your self hate." Another user emphasized the fat acceptance movement's value of being natural: "This is what us real girls look like. We don't wake up looking 'on fleek' and we love ourselves!" Emphasizing the group's "realness" sends an implicit message that other users who spend time trying to change their bodies are fake. Lastly, members of the fat acceptance movement looked down on anyone who was struggling with the stigma and felt badly about themselves. For example, one user wrote a post about how she had recently gained weight and felt uncomfortable about it. A fat acceptance advocate responded: "You should really believe in yourself and love yourself more." This suggests disapproval for anyone who is ashamed of their body and has internalized their weight to be a problem.

Inter-group disagreements on fat acceptance values. It is not surprising that outsiders of the fat acceptance movement would dispute this community's public avocation for changing social norms. One way that this took place was when outside members challenged their standards of beauty ( $28 \%$ of posts). This typically occurred by sending insulting messages to those individuals who displayed their bodies in order to make a statement (i.e. the \#fatikini posts). For example, a commenter wrote on an image of a woman's \#fatkini: "You shouldn't wear a bikini ever." A number of users commented back in the user's defense; for example, one user wrote, "I think that she's gorgeous and you're obviously jealous!" In addition to users' looks, there was often conflict about the meaning and standard of health. One user commented on a \#fatkini picture: "There is healthy and there is unhealthy. This isn't healthy, I'm sorry." These arguments often centered on the distinction of being overweight and eating healthy. For example, when a commenter told a user to "embrace eating healthy," members of her network spoke to her defense by arguing that she eats a vegan diet. Finally, outside commenters often spoke against the fat acceptance community by arguing that they should not glorify obesity. For instance, one user commented: "We really need to stop glorying FAT and appreciate the hard work and determination it takes for women to achieve a fit body." The fat acceptance community defended members of their movement by telling the commenter to "get off our pages."

\section{Out-Group Rejection: Pro-Ana}

Reporting. The pro-anorexic posts did not seem to depict any direct or intentional messages that were targeted toward the values of outside parties. However, these users emphasized the differences between outside groups during times in which their group was being threatened. The pro-anorexic community posts differed from the 
body positive image posts in that they often discussed the threat of being reported (36\% percent of posts; see table 2). Being reported is a threat to Instagram users because it can cause their accounts to be removed from the platform. A number of users would write posts that disclosed their previous account names. These users sent specific messages to their audience regarding how they should respond if they disagreed with their proanorexic content. For example, one user pleaded: "Don't report just block me!" Another user shared a screenshot notification from Instagram, which explained that she had been reported. She captioned her image: "If you don't like my account please leave it...reporting me isn't gonna change me." These posts reflect the wish for members of Instagram's pro-anorexic community to be uninterrupted by outsiders.

Recoverers. The second type of intervention that pro-anorexics received was from outsiders who were recovered anorexics. As noted in table 2, there were $16 \%$ of these types of posts. These outsiders interjected into the community through messages that conveyed concern regarding the ideologies that were being spread. Recovered anorexics had been through a traumatic experience and aimed to encourage other individuals not to go down the same path. These messages were often targeted towards individuals who were newly pro-anorexic or individuals who were on the fence about joining the community. For example, one user urged: "Please don't go that way...don't waste your life struggling with an eating disorder." Other recovered anorexics wrote comments related to their fear that pro-anorexic content can harm other groups. The following dialogue indicated a threat to pro-anorexics to keep their content off Instagram:

Jess450: Either cut it out or get the hell off the site!

Ano_11: People can do whatever they want. These [posts] are triggers and everyone already knows that.

Jess450: But it's harmful to others.

Similar to the user above, outsiders encouraged other users to stay away from the pro-ana content. For example, one user pleaded to another user not to look at "all those thinspo pics." These types of interactions reflected an attempt by outsiders to shut down the pro-anorexic community and to minimize their impact on the photo-sharing site of Instagram.

Beauty and bones. Similar to the fat acceptance community, pro-anorexics engaged in conflict with outsiders due to conflicting values. The value of beauty was often disputed as outsiders wrote comments disagreeing with the pro-anorexic ideal of an emaciated physique (65\% of posts). These comments were often a response to users' thinspiration images. One user posted a "thinspo" image captioned, "perfection," which received outside comments of "ew" and "gross." In addition, outsiders made comments of disgust on images of pro-anorexics' own bodies. For example, one user posted a full body mirror shot that displayed a bony body in a bra and underwear. An outside commenter insulted her by writing: "WTF. Are you on meth?"

The norm of thinness was also contested among users. Pro-anorexic users did not respond favorably when outsiders told them that they looked like they did not need to lose weight. Rather than accepting compliments from outside users, they made a point to dispute those individuals. For example, one user posted an image of herself and wrote the caption: "I look pregnant." When an outsider commented that her stomach looked tiny, she responded: "No...I'm sucking in so hard." These types of interactions contrasted with the reactions of fat acceptance users, who appeared more appreciative of compliments in their comment sections.

Healthy eating and glorification. Lastly, pro-anorexic users disputed on the standards of a healthy diet (18\% of posts). These arguments were based on the proper way to eat, exercise and lose weight. One disagreement centered on the correct amount of calories one should eat. This took place when a user disclosed that she was proud of her intake of 500 calories. A commenter warned that eating 500 calories would cause the user to slow her metabolism and suggested that she have 1,200-1,500 calories. This received a defensive comment from the individual who posted the image: "I hope you realize that I know what I'm doing, and from what I've been doing I've been losing weight." This user's reaction suggests the pro-anorexic group believes that they have a particular knowledge of weight-loss that outsiders do not have. Finally, outsiders disputed the way in which pro-anorexics reframed anorexia and self-harm to be seen as a positive aspiration. One outside user posted a meme that said: "If you could stop comparing Ed's [eating disorders] and self harm to 'going to wonderland,' that would be great." Others would write comments on pro-anorexic posts to stop glorifying a mental illness. The pro-anorexics would 
often deny having a mental illness and would reframe anorexia as a choice by claiming that it could be controlled.

Table 1. Percentage of total posts for RQ1 and RQ2 (Fat Acceptance Sample).

\begin{tabular}{lcc}
\hline Finding & Number of Posts & \% of Posts \\
\hline Identification & 260 & $65 \%$ \\
Positivity and self-love & 228 & $57 \%$ \\
Reframing beauty & 180 & $45 \%$ \\
Rejecting the status quo & 148 & $37 \%$ \\
Comparisons with other women & 140 & $35 \%$ \\
Inter-group disagreements & 112 & $28 \%$ \\
\hline
\end{tabular}

Table 2. Percentage of total posts for RQ1 and RQ2 (Pro-Anorexic Sample).

\begin{tabular}{lcc}
\hline Finding & Number of Posts & \% of Posts \\
\hline Weight loss ethic and thinspiration & 244 & $61 \%$ \\
Identification & 216 & $54 \%$ \\
Beauty and bones & 180 & $45 \%$ \\
Reporting & 144 & $36 \%$ \\
Negativity & 124 & $31 \%$ \\
Healthy eating and glorification & 72 & $18 \%$ \\
Recoverers & 64 & $16 \%$ \\
\hline
\end{tabular}

\section{Support: Fat Acceptance}

Esteem support. In relation to RQ3, findings showed that a prominent type of support within the fat acceptance community was esteem support. As noted in table 3, this type of support was seen in $29 \%$ of user posts. This often occurred through compliments and validation of other members of the community:

Compliments on appearance. One common type of compliment was to send encouraging responses regarding users' physical appearance ( $20 \%$ of posts). This typically occurred when users posted mirror shots and full-length shots of their bodies. Users often lent support by commenting, "beautiful," "gorgeous" and "sexy." Other comments referred to users' bodies; for example, one user wrote: "You have a beautiful body! You should be proud!" These comments may serve to boost the esteem of the entire community by encouraging members to be proud of their fuller figures. Other types of comments focused on individual body parts, such as: "You legit have the sexiest legs on insta!" or "great tummy!" These types of comments often focused on reframing users' flaws to be beautiful. For instance, one user shared a close-up image of the stretch marks on her stomach. She received a comment that said: "I hope this doesn't sound weird, but your stretch marks are beautiful!" The user responded, "I take that as a true compliment. I got them from my babies <3." These types of interactions emphasize the importance of celebrating flaws and not being ashamed of them.

Validation and inspiration. The second form of esteem support involved validating users for their boldness and confidence ( $9 \%$ of posts). Users often validated others for having the courage to speak their mind or to wear something that was out of their comfort zone. One post featured an image of a woman wearing no pants (in an underwear bottom). She received supportive comments such as, "I wish I were that brave," and "I would be worried that people would start running!" The theme of inspiration was recurring in a number of user comments. Users often thanked the person posting the image for inspiring them to feel comfortable about their own bodies. One example occurred when a user posted a picture of herself in a bra and underwear, with a caption that explained that she had recently given birth. She received the comment: "You and your campaign to accept ALL post-partum bodies and all variations of normal makes me feel better about myself. You are my inspiration!" By revealing how fat acceptance members have been instrumental in raising each other's body esteem, it provides further support for the community to continue its objective. 
Emotional support: Empathy and encouragement. Emotional support was present in fat acceptance posts in which users conveyed their empathy for each other's struggles. These comments were often empathetic of being marginalized or shamed in society. For example, some users complained about the fact that certain stores did not carry clothing in their size or did not make specific items to fit their body type. One shared an image of a bikini and complained that the suit did not support her breasts. Another user conveyed her empathy by commenting: "I know the struggle." The second form of emotional support involved encouraging messages to fellow fat acceptance members. Individuals often reiterated the notion of remaining positive and confident. For instance, one user posted an image of herself smiling in a bikini, with the following caption: "Learn to love the skin you're in. Other people love you just as you are!" This caption serves to support members of the fat acceptance movement to continue working on their journey towards achieving self-acceptance.

Informational support: Does this come in my size? Lastly, informational support was present in which users sought and received advice on where to buy clothing for their body types (24\% of posts). Users would often comment on the clothes worn by fat acceptance users and would ask for information on whether the item would come in their size. For example, one commenter asked whether an individual's dress would be available in her size, which was a UK 20. The user responded that she was a UK 24 (which translated to a $3 \mathrm{x}$ ) and provided advice for the commenter to purchase a $1 \mathrm{x}$. In addition to tips and advice, users would often provide reference support by referring others to certain stores that carried clothing to fit their frames. For example, users often provided links to plus-size websites such as ASOS curve and Torrid.

Table 3. Percentage of total posts for RQ3 (Fat Acceptance Sample).

\begin{tabular}{ccc}
\hline Finding & Number of Posts & \% of Posts \\
\hline Esteem support & $\mathbf{1 1 6}$ & $\mathbf{2 9 \%}$ \\
- Compliments & 80 & $20 \%$ \\
- Validation & 36 & $9 \%$ \\
Emotional support & $\mathbf{6 4}$ & $\mathbf{1 6 \%}$ \\
- Empathy & 36 & $9 \%$ \\
- Encouragement & 28 & $7 \%$ \\
Informational support & $\mathbf{9 6}$ & $\mathbf{2 4 \%}$ \\
- References & 44 & $11 \%$ \\
- Suggestions/advice & 52 & $13 \%$ \\
Total posts containing social support & $\mathbf{2 7 6}$ & $\mathbf{6 9 \%}$ \\
\hline
\end{tabular}

\section{Support: Pro-Ana}

Esteem support: \#Goals (compliments) and "likes" (validation). Similar to the fat acceptance movement, proanorexic users provided esteem support by complimenting others' bodies and conveying the notion of inspiration. As seen in table 4, this type of support took place in $26 \%$ of user posts. One recurring theme was the concept of "goals," which was often displayed in users' comment sections. This occurred when users would post images of their own bodies. For instance, a user posted an image of her own legs (looking emaciated) and received the comment: "Your legs are goals." Other users would simply respond to posts of bodies with the word "goals" or the hashtag \#goals. These responses conveyed support for users by suggesting that they have achieved a goal worthy body.

In contrast to the fat acceptance movement, pro-anorexic user posts often had explicit discussions about receiving "likes" as a form of support. These posts articulated the importance of receiving "likes" for the motivation of users to continue on their anorexic quests. Popular memes that were often circulated depicted images of skinny legs and stomachs with quotes such as " $1<3=2$ days without junk food/sweets" or " 1 like=1 hour of fasting." Users would often express their wish for "likes" with explicit captions; for example, one user wrote, "Please like!" These posts suggest the importance of validation for the pro-anorexic community, who may otherwise not feel validated by outsiders or intervening parties. 
Network support: Companionship and "ana buddies." Pro-anorexic posts reflected support regarding companionship with other anorexic individuals (11\% of posts). There was often a discussion about starting fasts or extreme diets as a community and losing weight together. For example, one commenter wrote, "I'm sure if we all work hard enough this summer we can lose 20 pounds!" This received a response that suggested: "We should all find a hobby to distract ourselves!" Others would write in their captions that users should direct message them if they would like to start a diet together. Lastly, a recurring theme was the notion of the "ana buddy," with hashtags such as \#anabuddy, \#anabuddywanted, and \#anabuddyneeded. The "ana buddy" is a pro-anorexic friend who accompanies and supports one's weight loss. These users would often offer to be each other's "ana buddies" and would write comments explaining their heights, weights and goal weights to see if they were compatible.

Emotional support: Concern for well-being and weight loss encouragement. Two contrasting types of emotional support were present in pro-anorexic user posts (11\% of posts). The first type of support reflected concern for each other's health and well-being. Despite the pro-anorexic ethic of self-destruction and harm, users conveyed concern for each other when commenting on posts that depicted extreme behaviors. For example, one user revealed in her caption that she had not eaten for 27 hours and planned to fast for another 21 hours. She received comments such as: "That's a really long time...you should eat a little snack, like an apple. Its only 60 calories!" Another user received a comment on a picture of her emaciated stomach that said: "Keep safe hun," to which she responded: "You too <3." This type of support suggests that pro-anorexic users have each other's safety in mind, despite (or because of) their extreme practices.

On the other hand, weight loss encouragement, the second form of support, served to encourage pro-anorexics to remain motivated and to continue working towards their weight-loss aspirations. For example, one user posted a "photo-collage" image of herself, with one picture of her actual body and another picture of her body sucking in. Her caption wrote: "Me on the left, and what I want to look like on the right." She received a number of responses of encouragement such as, "you will get there in no time," and "you fight the dream!" Another user posted an image of her legs and revealed that she hated the way they looked in her caption. Rather than complimenting her legs, she received a comment that said, "please don't give up!" These types of posts showed pro-anorexics that their community was supportive of their achievements.

Informational support: Ana tips and tricks. Lastly, the most common form of support for pro-anorexics occurred when users provided each other different forms of advice (32\% of posts). This included appraisal support in which users sought help on how to encounter situations in which their anorexia might be revealed. One user explained that she had a "weigh in" the following day and asked for tips on how to make herself appear heavier. Her question received numerous suggestions, such as wearing ankle weights, drinking lots of water and putting coins in her shoes. Another user received advice from her network on how to approach an upcoming high calorie family dinner. Her followers suggested that she take little bites, make lots of conversation and clear the dishes so that she could throw out the majority of her meal.

Pro-anorexic users often provided one another with tips and tricks for losing weight. These users explained their weight loss progress and provided details about their own diets. For example, one user posted a "photo-collage" that featured two images of herself in a bra and underwear. The image on the left was from " 3 weeks ago," while the image on the right was her current body, which was noticeably thinner. When asked by a commenter how she achieved her results, the user explained that she had been doing "water fasting" and eating low calorie meals. Other users posted general anorexic tips using memes labeled, "ana tips." For example, one meme wrote: "Ana tip: wear a rubber band around your wrist and snap it when you feel hungry." These posts provided information about how to remain motivated and how stay on track for losing weight. 
Table 4. Percentage of total posts for RQ3 (Pro-Anorexic Sample).

\begin{tabular}{ccc}
\hline Finding & Number of Posts & $\mathbf{\%}$ of Posts \\
\hline Esteem support & $\mathbf{1 0 4}$ & $\mathbf{2 6 \%}$ \\
• Compliments & 68 & $17 \%$ \\
• Validation & 36 & $9 \%$ \\
Network support & $\mathbf{3 6}$ & $\mathbf{9 \%}$ \\
• Companionship & 36 & $9 \%$ \\
Emotional support & $\mathbf{4 4}$ & $\mathbf{1 1 \%}$ \\
- Empathy & 28 & $7 \%$ \\
- Encouragement & 16 & $4 \%$ \\
Informational support & $\mathbf{1 2 8}$ & $\mathbf{3 2 \%}$ \\
- Suggestions/Advice & 72 & $18 \%$ \\
- Situation appraisals & 28 & $7 \%$ \\
- Teaching & 28 & $7 \%$ \\
Total posts containing social support & $\mathbf{3 1 2}$ & $\mathbf{7 8 \%}$ \\
\hline
\end{tabular}

\section{Discussion}

The findings above provide theoretical implications for social identity theory (Tajfel, 1978; Tajfel \& Turner, 1979) by revealing how body image standards are maintained in online communities. The communities within this study indicate overlapping tactics used to convey affiliation, reinforce solidarity, raise esteem and distinguish against outsiders. Both groups used the strategy of labeling themselves through hashtags. This illustrates the idea that creating social categories functions to accentuate the contrast between inter-group differences (Tajfel, 1969; Turner, 1985, 1999). Research has found that using the health label of "obese" can separate an individual as someone who disagrees with the fat acceptance movement (Ernsberger \& Haskew, 1997). Similarly, there are major differences between the labels of "pro-anorexic" and "recovered anorexic," as the former promotes maintaining anorexia, while the latter promotes overcoming anorexia (Riley et al., 2009). In this study, labels such as "team bbw" created an opposition with all groups who find a thin physique to be beautiful. Labels such as "secretsociety" created an exclusive community that opposes individuals who find anorexia to be a dangerous or deviant behavior. This tactic is consistent with previous studies on pro-ana groups, in which members advise one another with ways of hiding their behavior from the outside world (Haas et al., 2011).

Additionally, each community compared their own group's physical characteristics, attitudes and values with outside groups in order to assert their worth (Tajfel, 1978). This extends the notion within social identity theory in which subordinating "the other is even more integrated into our identities" (Briscoe, 2005, p. 9). For example, both groups engaged in conflict with outsiders on whether their body types should be considered beautiful. Ingroup members defended their standard of beauty by complimenting those who fit the ideal, while out-group members contested those values through insulting comments. This social comparison process also occurred when members of the in-group argued with outsiders about the meaning of health. Fat acceptance posts showed disagreements about whether a large body size was healthy, while pro-anorexic posts showed disagreements about whether an emaciated body size was healthy. This reflects the notion that members of these groups convey alternative viewpoints regarding the connection among the body, food and social norms (Smith, Wickes, \& Underwood, 2013).

Finally, it is not surprising that both groups conveyed a high amount of esteem support. This form of support was probably due to the groups' desire to maintain and enhance their social self-esteem and ideologies of health (Rubin \& Hewstone, 1988). Studies have shown that pro-ana communities receive esteem support from members of their networks, which acts as "feeding the obsession" of anorexia (Yeshua-Katz \& Martins, 2013, p. 505). This form of support provides an important source of confirmation that pro-ana's should be proud of achieving their weight loss goals and minimizes the idea that their efforts can be seen as extreme and unhealthy (Tong et al., 2013). Similarly, members of the fat acceptance movement also provide support for each others' beliefs that being overweight does not equate to living an unhealthy life; for example, fat acceptance members contest the use of a BMI (body mass index) as an accurate form of health measurement (Harding, 2007). A 
platform such as Instagram provides an ideal space for users to spread their messages through a combination of images, captions, hashtags and comments. Users can post a message that is in line with their social group and can receive "likes" and comments that affirm their position.

Both groups in this analysis also used this strategy in order to uphold their own standards of beauty and body image. This reflects additional strategies used by members of both the fat acceptance and pro-anorexic communities. For example, members of the pro-ana community have been known to circulate ideologies that they should reach a perfected standard of beauty by achieving a "goal weight" (Figueras Bates, 2015). Members of the fat acceptance community have been known to convey their ideology of beauty by reinventing standards of inclusion for clothing and fashion. For instance, "fatshion" blogs and "fatshion" shows serve to demonstrate that clothing can look beautiful on women with bigger bodies (Dailey, 2011; Peters, 2014). This study demonstrates how complimenting a fat acceptance member on her curves or telling a pro-anorexic member that her skinny thighs are "goals" can serve to frame each group with a positive value. Using tactics of validation can also illustrate to members of each group that their beliefs are "right."

As with most content analyses on social network sites, there are several limitations to sampling a community of online posts. One limitation to this study was based on using hashtags to collect public data. Using a sample of five hashtags from each community limits the opportunity to find important content that is posted elsewhere. This study relied on a small sample of hashtags as a precaution for not mistaking outsiders to be a part of each social category. Having a limited amount of public information about the most prominent hashtags for both communities caused me to make judgments based on the quantity of posts and criterion of content. Finding the most popular pro-anorexic posts became further complicated because the hashtags are constantly deleted by administrators of social media platforms. Future studies should assess additional examples of hashtags to discern whether the content remains consistent to the findings in this study. Additional research should also compare the community posts on multiple platforms in order to distinguish whether certain themes persist in various domains.

Another question that emerged based on sampling was the lack of a noticeable male presence in user posts $(0 \%)$. The female dominance of these communities demonstrates how women feel significantly more pressure to achieve a particular body size and are reported to have higher levels of body dissatisfaction than men (Lokken, Ferraro, Kirchner, \& Bowling, 2003). Women are known to both engage in and experience extreme body shaming based on messages from their parents, the media and their peers (Daye, Webb, \& Jafari, 2014; McKinley \& Hyde, 1996; McKinley, 1999). However, men are also socialized to achieve an "ideal" male body in more subtle ways (Hendry \& Giles, 1978; Parks \& Read, 1997). Therefore, further research should be conducted to ascertain whether these communities might have a minority of male members and whether the strategies used by each gender vary. I was also unable to capture demographic information of this sample in relation to age, race or class. I recommend that other scholars assess whether these characteristics are salient for members of each community.

Lastly, there are particular values and norms that cannot be identified from social media posts alone. Future studies should triangulate these findings with interviews in order to understand the motivations and intentions for particular posts as well as the importance of photo-sharing for each group's social identity. Ethnographic studies of these communities can also provide a deeper insider perspective. For example, previous ethnographies have examined the fat acceptance movement in face-to-face contexts (Klein, 1996; Millman, 1980). For instance, Cooper's (2012) autoethnography of a fat activist workshop found intra-group tensions among members of different body weights. Updating these findings to consider digital spaces (such as the fatosphere) would help elucidate how these communities use different platforms to spread their messages. However, it is also complicated to gain access to the community of pro-anorexics because of their distrust of outsiders. Overcoming this barrier would provide rich information for researchers to continue comparing how communication strategies used by the pro-anorexic community overlap with communication strategies used by the fat acceptance movement.

Despite its methodological limitations, the present study provides vital insight into the way in which different groups attempt to cope with pressures of body image in our society. By boosting the esteem of one's social identity, individuals can either reappropriate standards of society's body ideal (such as the fat acceptance 
community) or accentuate the importance of going to extreme lengths to conform to society's body ideal. This ability becomes further magnified through use of social media, which allows users to reach a wide audience from a variety of geographical locations. Future studies on these mediated communities would have valuable implications for activists, health researchers and medical practitioners who aim to educate others about the processes of body image dissatisfaction.

\section{Note}

1. It is important to note that popular pro-anorexic hashtags are often removed from the application of Instagram because of their graphic content. Therefore, the community tends to create loopholes by reappropriating previous hashtags (such as changing the hashtag of \#proana to \#proanaa).

\section{Acknowledgement}

I am grateful to Dr. Jeffrey Lane for his insightful comments and useful feedback on earlier versions of this manuscript.

\section{References}

Anderson, J. (2012). Whose voice counts? A critical examination of discourses surrounding the body mass index. Fat Studies: An Interdisciplinary Journal of Body Weight and Society, 1, 195-207.

http://dx.doi.org/10.1080/21604851.2012.656500

Bane, C. M., Haymaker, C., \& Zinchuk, J. (2005). Social support as a moderator of the bigfish in a little pond effect in online self help support groups. Journal of Applied Biobehavioral Research, 10, 239-261.

Bartky, S. (1990). Femininity and domination: Studies in the phenomenology of oppression. New York, NY: Routledge.

Boero, N., \& Pascoe, C. J. (2012). Pro-anorexia communities and online interaction: Bringing the pro-ana body online. Body \& Society, 18(2), 27-57. http://dx.doi.org/10.1177/1357034X1244082

Borzekowski, D. L., Schenk, S., Wilson, J. L., \& Peebles, R. (2010). E-Ana and e-Mia: A content analysis of pro-eating disorder web sites. American Journal of Public Health, 100, 1526-1534.

http://dx.doi.org/10.2105/AJPH.2009.172700

Bowers, K. (2010, April 4). Fat acceptance: Can you be healthy at any size? Women's Health. Retrieved from http://www.womenshealthmag.com/health/fat-acceptance

Briscoe, F.M. (2005). A question of representation in educational discourse: Multiplicities and inter-sections of identities and positionalities. Educational Studies, 38(1), 23-41. http://dx.doi.org/10.1207/s15326993es3801_4

Brotsky, S. R., \& Giles, D. (2007). Inside the "pro-ana" community: A covert online participant observation. Eating Disorders, 15, 93-109. http://dx.doi.org/10.1080/10640260701190600

Brown, L. (1989), Fat-oppressive attitudes and the feminist therapist: Directions for change.Women and Therapy: A Feminist Quarterly, 8(3), 19-30.

Campos, P. (2005). The diet myth: Why America's obsession with weight is hazardous to your health. New York, NY: Penguin. 
Carr, D., \& Friedman M.A. (2005). Is obesity stigmatizing? Body weight, perceived discrimination, and psychological well-being in the United States. Journal of Health and Social Behavior, 46, 244-259. http://dx.doi.org/10.1177/002214650504600303

Chesley, E. B., Alberts, J., Klein, J., \& Kreipe, R. (2003). Pro or con? Anorexia nervosa and the Internet. Journal of Adolescent Health, 32, 123-124.

Chou, W. Y. S., Prestin, A., \& Kunath, S. (2014). Obesity in social media: A mixed methods analysis. Translational Behavioral Medicine, 4, 314-323.

Cooper, C. R. M. (2012). Fat activism: A queer autoethnography [doctoral dissertation]. University of Limerick. Retrieved from http://hdl.handle.net/10344/2823

Corbin, J., \& Strauss, A. (2014). Basics of qualitative research: Techniques and procedures for developing grounded theory. Thousand Oaks, CA: Sage publications.

Csipke, E., \& Horne, O. (2007). Pro-eating disorder websites: Users' opinions. European Eating Disorders Review, 15, 196-206. http://dx.doi.org/10.1002/erv.789

Cutrona, C. E., \& Suhr, J. A. (1994). Social support communication in the context of marriage: an analysis of couples' supportive interactions. In B. R. Burleson, T. L. Albrecht, \& I. G. Sarason (Eds.), Communication of social support: Messages, interactions, relationships, and community (pp. 113-135). Thousand Oaks, CA: Sage Publications.

Dailey, K. (2011, January). 'Fatshion' blogs defiantly celebrate plus-size couture. BBC. Retrieved from http://www.bbc.co.uk/news/magazine-16259070

Daye, C. A., Webb, J. B., \& Jafari, N. (2014). Exploring self-compassion as a refuge against recalling the bodyrelated shaming of caregiver eating messages on dimensions of objectified body consciousness in college women. Body Image, 11, 547-556. http://dx.doi.org/10.1016/j.bodyim.2014.08.001

Dias, K. (2013). The ana sanctuary: Women's pro-anorexia narratives in cyberspace. Journal of International Women's Studies, 4(2), 31-45.

Dickins, M., Thomas, S. L., King, B., Lewis, S., \& Holland, K. (2011). The role of the Fatosphere in fat adults' responses to obesity stigma: A model of empowerment without a focus on weight loss. Qualitative Health Research, 21, 1679-1691. http://dx.doi.org/1049732311417728

Ellemers, N., \& Haslam, S. A. (2011). Social identity theory. In P. A. Van Lange, A. W. Kruglanski, \& T. Higgins (Eds.), Handbook of theories of social psychology: Volume two (pp. 379-398). Thousand Oaks, CA: Sage.

Ernsberger, P., \& Haskew, P. (1987). Health implications of obesity: An alternative view. Journal of Obesity and Weight Regulation, 6(67), 58-137.

Falk, G. (2001). Stigma: How we treat outsiders. Amherst, NY: Prometheus Books.Figueras Bates, C. (2015). “I am a waste of breath, of space, of time": Metaphors of self in a pro-anorexia group. Qualitative Health Research, 25, 189-204. http://dx.doi.org/10.1177/1049732314550004

Gavin, J., Rodham, K., \& Poyer, H. (2008). The presentation of "pro-anorexia" in online group interactions. Qualitative Health Research, 18, 325-333. http://dx.doi.org/10.1177/1049732307311640

Giles, D. (2006). Constructing identities in cyberspace: The case of eating disorders. British Journal of Social Psychology, 45, 463-477. http://dx.doi.org/10.1348/014466605X53596

Giles, D. C., \& Newbold, J. (2010). Self- and other-diagnosis in user-led mental health online communities. Qualitative Health Research, 21, 419-428. http://dx.doi.org/10.1177/1049732310381388 
Glaser, B., \& Strauss, A. (1967). The discovery grounded theory: Strategies for qualitative inquiry. Chicago, IL: Aldine.

Goffman, E. (1963). Stigma: Notes of the management of spoiled identity. New York, NY: Simon and Schuster.

Gurrieri, L., \& Cherrier, H. (2013). Queering beauty: Fatshionistas in the fatosphere. Qualitative Market Research: An International Journal, 16, 276-295. http://dx.doi.org/10.1108/13522751311326107

Haas, S. M., Harding, M. E., Jennings, N. A., \& Wagner, L. M. (2010). Online negative enabling support groups. New Media \& Society, 13, 40-57. http://dx.doi.org/10.1177/1461444810363910

Harding, K. (2007). BMI project. Shapely Prose. Retrieved from http://kateharding.net/bmi-illustrated/

Harding, K., \& Kirby, M. (2009). Lessons from the fat-o-sphere: Quit dieting and declare a truce with your body. New York, NY: Penguin.

Harper, K., Sperry, S., \& Thompson, J. (2008). Viewership of pro-eating disorder websites: Association with body image and eating disturbances. International Journal of Eating Disorders, 41, 92-5.

http://dx.doi.org/10.1002/eat.20408

Harshbarger, J. L., Ahlers-Schmidt, C. R., Mayans, L., Mayans, D., \& Hawkins, J. H. (2009). Pro-anorexia websites: What a clinician should know. International Journal of Eating Disorders, 42, 367-370.

http://dx.doi.org/10.1002/eat.20608

Hendry, L. B., \& Gillies, P. (1978). Body type, body esteem, school, and leisure: A study of overweight, average, and underweight adolescents. Journal of Youth and Adolescence, 7, 181-195.

Hogg, M. A., \& Abrams, D. (1988). Social identifications: A social psychology of intergroup relations and group processes. Florence, KY: Taylor \& Frances/Routledge.

Instagram. (2016, January 22). Our story. Instagram. Retrieved from https://www.instagram.com/press/?hl=en

Juarascio, A. S., Shoaib, A., \& Timko, C. A. (2010). Pro-eating disorder communities on social networking sites: A content analysis. Eating Disorders, 18, 393-407. http://dx.doi.org/10.1080/10640266.2010.511918

Katz, M. (2009, July 15). Tossing out the diet and embracing the fat. The New York Times. Retrieved from http://www.nytimes.com/2009/07/16/health/nutrition/16skin.html

Kirkland, A. (2008). Fat Rights: Dilemmas of difference and personhood. New York: New York University Press.

Klein, R. (1996). Eat fat. New York: Pantheon Books.

Knapton, O. (2013). Pro-anorexia: Extensions of ingrained concepts. Discourse \& Society, 24, 461-477. http://dx.doi.org/10.1177/0957926513482067

LaCoursiere, S. P. (2001). A theory of online social support. Advances in Nursing Science, 24, 60-77.

http://dx.doi.org/10.1097/00012272-200109000-00008

LeBesco, K. (2004). Revolting bodies: The struggle to redefine fat identity. Amherst, MA: University of Massachusetts Press.

LeBesco, K., \& Braziel, J. E. (2001) Editors introduction. In J. E. Braziel \& K. LeBesco (Eds.), Bodies out of bounds: Fatness and transgression. University of California Press: Berkeley, CA.

Lipczynska, S. (2007). Discovering the cult of ana and mia: a review of pro-anorexia websites. Journal of Mental Health, 16, 545-548. 
Lokken, K., Ferraro, F. R., Kirchner, T., \& Bowling, M. (2003). Gender differences in body size dissatisfaction among individuals with low, medium, or high levels of body focus. The Journal of General Psychology, 130, 305310. http://dx.doi.org/10.1080/00221300309601161

Lyons, E. J., Mehl, M. R., \& Pennebaker, J.W. (2006). Pro-anorexics and recovering anorexics differ in their linguistic Internet self-presentation. Journal of Psychosomatic Research, 60, 253-256.

http://dx.doi.org/10.1016/j.jpsychores.2005.07.017

Mantella, D. G. (2007). "Pro-Ana" web-log uses and gratifications: Towards under- standing the pro-anorexia paradox [masters thesis]. Georgia State University, Atlanta, GA.

McDonell-Parry, A. (2009, June 17). Does the fat acceptance movement glamorize an unhealthy lifestyle? The Frisky. Retrieved from http://www.thefrisky.com/2009-06-17/does-the-fat-acceptance-movement-glamorize-anunhealthy-lifestyle/

McKinley, N. M. (1999). Women and objectified body consciousness: mothers' and daughters' body experience in cultural, developmental, and familial context. Developmental Psychology, 35, 760-769.

http://dx.doi.org/10.1037/0012-1649.35.3.760

McKinley, N. M., \& Hyde, J. S. (1996). The objectified body consciousness scale development and validation. Psychology of Women Quarterly, 20,181-215. http://dx.doi.org/10.1111/j.1471-6402.1996.tb00467.x

Millman, M. (1980). Such a pretty face, being fat in America. New York, NY: Norton Press.

Murray, S. (2005). Doing politics or selling out? Living the fat body. Women's Studies, 34, 265-277. http://dx.doi.org/10.1080/00497870590964165

Myers, A. M., \& Rothblum, E. D. (2010). Coping with prejudice and discrimination based on weight. In J. L. Chin (Ed.), The psychology of prejudice and discrimination (pp. 187-197). Santa Barbara, CA: Praeger.

Norris, M. L., Boydell, K. M., Pinhas, L., \& Katzman, D. K. (2006). Ana and the Internet: A review of pro-anorexia websites. International Journal of Eating Disorders, 39, 443-447. http://dx.doi.org/10.1002/eat.20305

Orbach, S. (1978). Fat is a feminist issue: How to lose weight permanently - Without dieting. London: Arrow Books.

Parks, P. S. M., \& Read, M. H. (1997). Adolescent male athletes: Body image, diet, and exercise. Adolescence, 32, 593-602.

Peters, L. D. (2014). You are what you wear: How plus-size fashion figures in fat identity formation. Fashion Theory, 18(1), 45-71. http://dx.doi.org/10.2752/175174114X13788163471668

Peng, T. (2008, November). Pro-anorexia groups spread to Facebook. Newsweek. Retrieved from http://www.newsweek.com/pro-anorexia-groups-spread-facebook-85129

Rabin, C. R. (2008, January 22). In the fatosphere, big is in, or at least accepted. New York Times. Retrieved from http://www.nytimes.com/2008/01/22/health/22fblogs.html

Riley, S., Rodham, K., \& Gavin, J. (2009). Doing weight: Pro-ana and recovery identities in cyberspace. Journal of Community \& Applied Social Psychology, 19, 348-359. http://dx.doi.org/10.1002/casp.1022

Rubin, M., \& Hewstone, M. (1998). Social identity theory's self-esteem hypothesis: A review and some suggestions for clarification. Personality and Social Psychology Review, 2, 40-62.

http://dx.doi.org/10.1207/s15327957pspr0201_3 
Satinsky, S., \& Ingraham, N. (2014). At the intersection of public health and fat studies: Critical perspectives on the measurement of body size. Fat Studies, 3, 143-154. http://dx.doi.org/10.1080/21604851.2014.889505

Smith, N., Wickes, R., \& Underwood, M. (2015). Managing a marginalised identity in pro-anorexia and fat acceptance cybercommunities. Journal of Sociology, 51, 950-967. http://dx.doi.org/10.1177/1440783313486220

Sobal, J., \& D. Maurer. (1999). Interpreting weight: The social management of fatness and thinness. New Jersey: Aldine.

Stets, J. E., \& Burke, P. J. (2000). Identity theory and social identity theory. Social Psychology Quarterly, 63, 224-237.

Stommel, W., \& Koole, T. (2010). The online support group as a community: A micro-analysis of the interaction with a new member. Discourse Studies, 12, 357-378. http://dx.doi.org/10.1177/1461445609358518

Stommel, W., \& Meijman, F. J. (2011). The use of conversation analysis to study social accessibility of an online support group on eating disorders. Global Health Promotion, 18(2), 18-26.

http://dx.doi.org/10.1177/1757975911404764

Saguy, A. C., \& Ward, A. (2011). Coming out as fat rethinking stigma. Social Psychology Quarterly, 74, 53-75. http://dx.doi.org/10.1177/0190272511398190

Sundar, S. S., Edwards, H. H., Hu, Y., \& Stavrositu, C. (2007). Blogging for better health: Putting the "public" back in public health. In M. Tremayne (Ed.), Blogging, citizenship, and the future of media (pp. 83-102). Routledge.

Tajfel, H. (1969). Cognitive aspects of prejudice. Journal of Biosocial Science, 1(S1), 173-191.

http://dx.doi.org/10.1111/j.1540-4560.1969.tb00620.x

Tajfel, H. E. (1978). Differentiation between social groups: Studies in the social psychology of intergroup relations. Waltham, MA: Academic Press.

Tajfel, H. (1979). Individuals and groups in social psychology. British Journal of Social and Clinical Psychology, 18, 183-190. http://dx.doi.org/10.1111/j.2044-8260.1979.tb00324.x

Tajfel, H., \& Turner, J. C. (1979). An integrative theory of intergroup conflict. In The Social Psychology of Intergroup Relations (pp. 30-47).

Thurlow, C., \& Bell, K. (2009). Against technologization: Young people's new media discourse as creative cultural practice. Journal of Computer-Mediated Communication, 14(4), 1038-1049. http://dx.doi.org/10.1111/j.10836101.2009.01480.x

Tierney, S. (2008). Creating communities in cyberspace: Pro-anorexia web sites and social capital. Journal of Psychiatric and Mental Health Nursing, 15, 340-343. http://dx.doi.org/10.1111/j.1365-2850.2007.01190.x

Tiller, J., Schmidt, U., Ali, S., \& Treasure, J. (1995). Patterns of punitiveness in women with eating disorders. International Journal of Eating Disorders, 17, 365-371. http://dx.doi.org/10.1002/1098-108X(199505)17:4<365::AIDEAT2260170408>3.0.CO;2-A

Tiller, J. M., Sloane, G., Schmidt, U., \& Troop, N. (1997). Social support in patients with anorexia nervosa and bulimia nervosa. International Journal of Eating Disorders, 21, 31-38. http://dx.doi.org/10.1002/(SICl)1098108X(199701)21:13.0.CO;2-4

Tong, S. T., Heinemann-Lafave, D., Jeon, J., Kolodziej-Smith, R., \& Warshay, N. (2013). The use of pro-ana blogs for online social support. Eating disorders, 21, 408-422. http://dx.doi.org/10.1080/10640266.2013.827538 
Teufel, M., Hofer, E., Junne, F., Sauer, H., Zipfel, S., \& Giel, K. E. (2013). A comparative analysis of anorexia nervosa groups on Facebook. Eating and Weight Disorders-Studies on Anorexia, Bulimia and Obesity, 18, 413-420.

Turner, J. C. (1985). Social categorization and the self-concept: A social cognitive theory of group behavior. In E. J. Lawler (Ed.), Advances in group processes (pp. 77-122). Greenwich, CT: JAI press.

Turner, J. C. (1999). Some current issues in research on social identity and self-categorization theories. In $\mathrm{N}$. Ellemers, R. Spears, \& B. Doosje (Eds.), Social identity: Context, commitment, content (pp. 6-34). Hoboken, NJ: WileyBlackwell.

Wardle, J., Waller, J., \& Fox, E. (2002). Age of onset and body dissatisfaction in obesity. Addictive Behaviors, 27, 561573.

Warin, M. (2009). Abject relations: Everyday worlds of anorexia. New Brunswick, NJ: Rutgers University Press.

Williams, C., \& Riley, S. (2013). Finding support and negotiating identity: An analysis of the structure and content of newbie posts and their elicited replies on five pro-eating disorder websites. RESET. Recherches en sciences sociales sur Internet, (2).

Yeshua-Katz, D., \& Martins, N. (2013). Communicating stigma: The pro-ana paradox. Health Communication, 28, 499-508. http://dx.doi.org/10.1080/10410236.2012.699889

Zeller, M. H., \& Modi, A. C. (2006). Predictors of health-related quality of life in obese youth. Obesity, 14, 122-130.

\section{Correspondence to:}

Sarah-Rose Marcus

4 Huntington street

New Brunswick

NJ 08901-1071

Email: sm1580(at)scarletmail.rutgers.edu

\section{About author}

Sarah-Rose Marcus is currently a doctoral student at Rutgers' School of Communication and Information. Her research examines the role that social media platforms play in identity construction and romantic relationship development. 